\title{
Use of the foraging area by captive bred oriental storks (Ciconia boyciana) in a closed semi natural paddy field
}

\author{
Jongmin Yoon ${ }^{1}$, Sang-Hee $\mathrm{Na}^{2}$, Su-Kyung Kim ${ }^{1}$ and Shi-Ryong Park ${ }^{1,2, *}$ \\ ${ }^{1}$ Korea Institute of Oriental White Stork Reintroduction Research Center, Korea National University of Education, Cheongwon \\ 363-791, Korea \\ ${ }^{2}$ Department of Biology Education, Korea National University of Education, Cheongwon 363-791, Korea
}

\begin{abstract}
Rice paddy fields have been recognized as an alternative habitat for avian wetland foragers, and fish-rice farms have become a new tool in improving the abundance of aquatic animals. However, the use of the habitats by avian foragers, particularly by oriental storks (Ciconia boyciana), was not well understood. In the present study, we investigated how a fish-rice farm influenced the abundance of aquatic animals and documented the foraging behavior of the two captive bred oriental storks in a closed semi-natural paddy field. Our results showed that the fish refuge pond (water depth 40 $\mathrm{cm}$ ) had a higher abundance of fish whereas the areas planted with rice (water depth $20 \mathrm{~cm}$ ) had more tadpoles and some aquatic insects. The two captive bred oriental storks captured mostly fish and aquatic insects in the rice-planted area and mostly fish in the fish refuge pond. The two oriental storks had higher foraging success and spent more time for foraging in the rice-planted area than in the fish refuge pond. This result suggests that the oriental storks might prefer foraging in the area with fish, aquatic insects, and amphibians under a greater success rate presumably due to shallow water depth in the paddy fields with a fish-rice farm.
\end{abstract}

Key words: Ciconia boyciana, fish-rice farm, food abundance, foraging success, paddy field, reintroduction

\section{INTRODUCTION}

Rice paddy fields have been recognized as an alternative wetland for water birds (reviewed in Lawler 2001, Czech and Parsons 2002). The loss of natural wetlands has been historically accelerated by the expansion of human activities, so agroecosystems, including human irrigated ponds, have become an important provider of resources for breeding avian species (Sebastián-González et al. 2010). Generally, rice paddy fields were used by agricultural wetland species in summer whereas river systems were likely substituted for the agricultural fields during late fall and winter (Choi et al. 2007, Amano et al. 2008). Furthermore, the abundance of birds that used rice paddy fields for foraging was found to vary with a flooding re- gime depending upon the agricultural schedules, such as irrigating the rice paddy fields during the spring and summer and draining them prior to harvesting in fall and through winter. To date, many studies have investigated the factors affecting the habitat use of bird species (Dorfman et al. 2001, Amano et al. 2008, Moreno-Opo et al. 2011) and have also examined the distribution of fish in the rice-paddy fields (Naruse and Oishi 1996, Hata 2002, Fujimoto et al. 2008, Kano et al. 2010, Katayama et al. 2011). However, the information necessary for understanding the relationships between the abundance of aquatic animals and avian wetland foragers is lacking with regards to habitat management.

\section{Open Access http://dx.doi.org/10.5141/JEFB.2012.010}

This is an Open Access article distributed under the terms of the Creative Commons Attribution Non-Commercial License (http://creativecommons. org/licenses/by-nc/3.0/) which permits unrestricted non-commercial use distribution, and reproduction in any medium, provided the original work is properly cited.
Received 23 December 2011, Accepted 13 January 2012

*Corresponding Author

E-mail: srpark@knue.ac.kr

Tel: +82-43-230-3719 

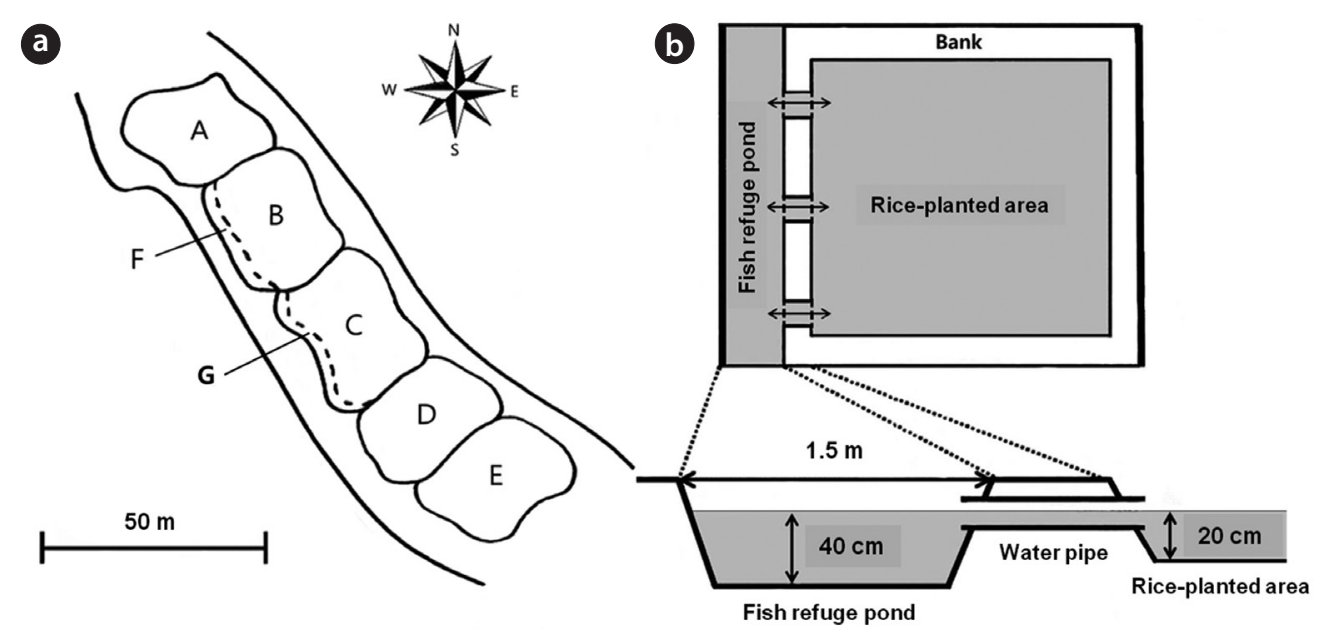

Fig. 1. The study area where we studied the foraging behavior of oriental storks (Ciconia boyciana) and investigated aquatic animal abundance in Miwon, Cheongwon, Chungbuk Province, Republic of Korea. (a) The area included the four types of foraging habitats: meadow (A), fish-rice farmed field (B, C), pond (water depth $50 \mathrm{~cm} ; \mathrm{D}$ ), and a shallow swamp (water depth $2 \mathrm{~cm}$; E). (b) Each fish-rice farmed field contained a rice-planted area (water depth $20 \mathrm{~cm}$ ) and a fish refuge pond (5-6\% of total area; water depth $40 \mathrm{~cm}$; see also $\mathrm{F}$ and $\mathrm{G}$ in Fig. 1a).

The oriental stork (Ciconia boyciana) is a large $(4-6 \mathrm{~kg})$ carnivorous wetland forager that eats fish, amphibians, insects, reptiles, small birds, and mammals. However, due to habitat degradation and overhunting in the past, the species has become internationally listed as endangered and are currently only breeding in Russia and partially in China (BirdLife International 2008). In South Korea, the last oriental stork individual died in the Seoul Zoo in 1994 after the loss of its mate hunting in the wild in 1971 (Park and Cheong 2002). The Korea Institute of Oriental White Stork Reintroduction Research Center (KIOWSRRC) was established in 1996 to propagate storks in captivity with plans to reintroduce a breeding population of the species in South Korea (Park and Cheong 2002, Park et al. 2010). Currently, the captive number of oriental storks has successfully exceeded one hundred, and the future reintroduction site, mainly in a large portion of the paddy fields of Yesan in Chungnam Province, has been constantly monitored and managed to ensure its aquatic biodiversity and fish abundance (Park et al. 2010). Our previous study showed that loaches (Misgurnus and Lefua spp.) preferred organic paddy fields or paddy fields with fish refuge ponds to conventional paddy fields or those without fish refuge ponds (Jung 2010). In addition, a mixed effect of loach abundance $(15,30$, and $45 \mathrm{~kg} /$ day) and water depth $(5,15$, and $30 \mathrm{~cm})$ was found on the foraging time and success of oriental storks in a semi natural space, including grassland, paddy field, shallow water swamp, and pond, but the results were less conclusive (Sung et al. 2009). The present study focused on the application of facilitated fish-rice farming that included fish refuge ponds inside paddy fields to understand the relationship between the prey abundance and the foraging behavior of oriental storks. We investigated how a fish-rice farm influenced aquatic animal abundance and foraging behavior of the captive bred oriental storks in the paddy fields. Such information on the foraging behavior and habitat use of the species should provide insight useful for future habitat management with respect to a successful wildlife reintroduction as one of the wildlife conservation tools.

\section{MATERIALS AND METHODS}

\section{Study area and subject}

Our study site was located in a part of the paddy fields in Miwon, Cheongwon, Chungbuk Province, Republic of Korea ( $\left.36^{\circ} 41^{\prime} 47^{\prime \prime} \mathrm{N}, 127^{\circ} 39^{\prime} 26^{\prime \prime} \mathrm{E}\right)$. The 0.42 hectare fenced area included two paddy fields $\left(1,962 \mathrm{~m}^{2}\right.$; water depth 20 $\mathrm{cm})$, one each of a meadow $\left(830 \mathrm{~m}^{2}\right.$; no water source), a pond $\left(570 \mathrm{~m}^{2}\right.$; water depth $\left.50 \mathrm{~cm}\right)$, and a shallow swamp (840 m²; water depth $2 \mathrm{~cm}$ ) (Fig. 1a). Each paddy field also contained a rice-planted area (water depth $20 \mathrm{~cm}$ ) and a fish refuge pond (5-6\% of the total paddy field area; water depth $40 \mathrm{~cm}$ ) that were connected for consistent water flows and aquatic animal movements (Fig. 1b). Here, the level of the filled water in the two paddy fields was partially regulated by the in and out flow of the water. Rice seedlings were planted in May 26th of 2009 prior to sampling the abundance of aquatic animals and the temporary introduction of the oriental storks. Two oriental storks 
(one of each sex) were randomly selected from the breeding facility in KIOWSRRC under the criterion that they be healthy after-second-year adults that weighted 4-6 kg (Table 1). The primary feathers on the right-side wing of both storks were clipped to temporarily limit their flight, but they were able to walk and still fly short distances, which was sufficient to use the fenced area. The two oriental storks were then released and observed in the study area from May 27th to August 10th of 2009.

\section{Aquatic animal abundance}

To assess the abundance of aquatic animals in the two paddy fields, we obtained samples of the aquatic animals in the rice-planted areas and the fish-refuge ponds using two types of traps twice a month from May to August of 2009. Fish lures ( $20 \mathrm{~g}$ per trap) were placed into cylindershaped commercial fish traps (length $28 \mathrm{~cm} \times$ diameter $14 \mathrm{~cm}$ ) and handmade 1.5-liter plastic bottle traps that contained a fluorescent stick for attracting fish or aquatic invertebrates during the night. The traps were randomly set in the rice-planted area and fish-refuge pond between 7:00 pm and 7:00 am of the next day. Sampling during the night was included because the nocturnal activities of loaches (Misgurnus spp.) were likely greater than their diurnal activities in paddy fields (Naruse and Oishi 1996). Four of each type of the traps were set in the rice-planted areas, and two of each type of the traps were set in the fish refuge pond. The aquatic animal samples from the traps were washed, identified, and counted in the field.

\section{Oriental stork foraging behavior}

Foraging behavior of the two oriental storks was recorded through a closed-circuit television (CCTV, model RS483; Sungjin Elecomm Co., Ltd., Gwangju, Korea). We transcribed the video files into location (see Fig. 1), prey types (i.e., fish, tadpoles, frog, and unknown small items), foraging success (i.e., the number of captures/total foraging attempts), and time that the oriental storks spent for foraging. In the analyses, the percentage of foraging time was adjusted by the area difference in the portion of rice-planted area (95\% of total paddy field area) and fish- refuge pond ( $5 \%$ of total paddy field area). Compared to bill-pecking behavior while calculating foraging success, we recorded a serious of bill-vibrating behavior in water as one foraging attempt. The number of prey captures by the oriental storks was counted by the occurrences of the behavior where the stork raised its bill from the water surface to swallow captured preys. Foraging observations from the two paddy fields in the study area were only included in the data analyses.

\section{Statistical analyses}

We used the nonparametric Wilcoxon signed-rank test to compare the abundance of aquatic animals, percent prey type, foraging success, and foraging time of the storks in the rice-planted area and the fish refuge pond under no assumption of normality. The behavioral data from the repeated observations of each individual were analyzed separately. All statistical analyses were performed in SPSS ver. 16 (SPSS Inc., Chicago, IL, USA). Data were presented as means \pm 1 standard error (SE).

\section{RESULTS}

\section{Aquatic animal abundance}

From our surveys, we had confirmed the existence of at least eight aquatic species from four animal classes (Table 2). The abundance of Japanese predacious diving beetles $(Z=-2.50, P=0.01)$ and amphibian tadpoles $(Z=-2.68$, $P=0.01$ ) was higher in the rice-planted area than in the fish refuge pond, while that of eight-barbel loaches $(Z=$ -2.90, $P<0.001)$ and Chinese muddy loaches $(Z=-2.34$, $P=0.02$ ) was higher in the fish-refuge pond (Table 2). The abundance of other animals was not different between the areas $(P s>0.05)$.

\section{Prey type, success rate, and foraging time of the oriental storks}

First, the two captive bred oriental storks captured mostly fish and unknown small preys (e.g., aquatic in-

Table 1. Body measurements of the two captive bred oriental storks (Ciconia boyciana) that were temporarily released into the study area

\begin{tabular}{lccccc}
\hline Sex & Hatch year & Bill length $(\mathbf{c m})$ & Tarsus length $(\mathbf{c m})$ & Wing length $(\mathbf{c m})$ & Body weight $(\mathbf{k g})$ \\
\hline Male & 2007 & 28.6 & 31.0 & 68.0 & 5.3 \\
Female & 2005 & 23.2 & 26.0 & 63.5 & 4.1 \\
\hline
\end{tabular}


sects) in the rice-planted area and fish refuge pond throughout the study period (Fig. 2). The frequency of capturing tadpoles and unknown small preys was significantly higher in the rice-planted area than in the fish refuge pond while the frequency of capturing other preys did not differ between the two areas (Table 3). Second, the foraging success rate of the male individual was higher in the rice-planted area $(89.05 \pm 2.45 \%)$ than in the fish refuge area (51.82 $\pm 7.25 \% ; Z=-3.94, P<0.001$ ) (Fig. 3a), and that of the female individual was also higher in the rice-planted area $(85.73 \pm 2.60 \%)$ than in the fish refuge pond (54.01 $\pm 8.02 \% ; Z=-3.10, P<0.01$ ) (Fig. 3a). Third, the male individual spent more time foraging in the riceplanted area (73.54 $\pm 3.24 \%)$ than in the fish refuge pond (26.46 $\pm 3.24 \%$; $Z=-9.91, P<0.001)$ (Fig. 3b), and the female individual also spent more time for foraging in the rice-planted area $(79.36 \pm 3.06 \%)$ than in the fish refuge pond $(20.64 \pm 3.06 \% ; Z=-3.94, P<0.001)$ (Fig. $3 b$ ).

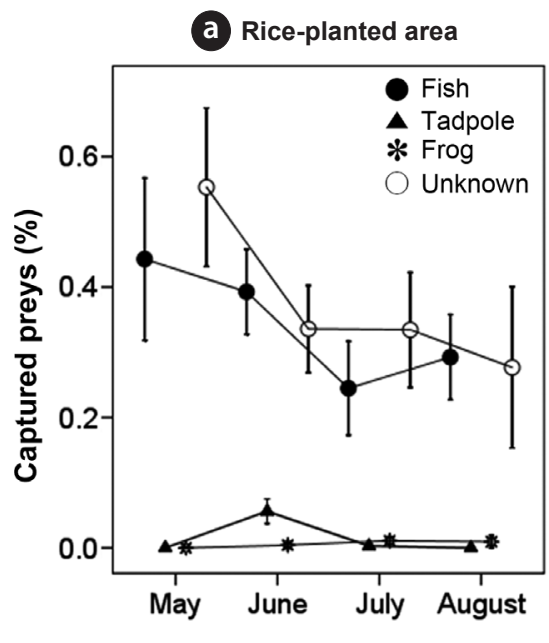

(b) Fish refuge pond

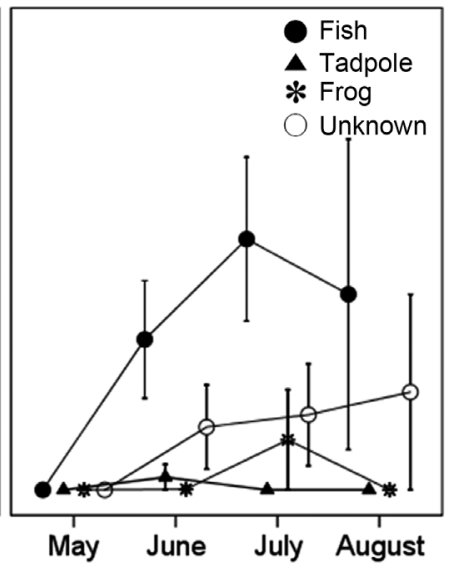

Fig. 2. Prey types captured by the two captive bred oriental storks released into the paddy fields with a fish-rice farm. Prey types from the video data included fish, like loaches, tadpoles, frogs, and unknown small items like aquatic insects that the oriental storks foraged in the rice-planted area (a) and fish refuge pond (b) from May to August of 2009. Each bar denotes mean \pm 1 SE.

Table 2. An abundance comparison of aquatic animals sampled from the rice-planted area and fish refuge pond in the two paddy fields with a fish-rice farm

\begin{tabular}{|c|c|c|c|c|c|}
\hline Class & Species & $\begin{array}{l}\text { Rice-planted area } \\
\qquad(N=14)\end{array}$ & $\begin{array}{l}\text { Fish refuge pond } \\
\qquad(N=14)\end{array}$ & $Z$ & $P$ \\
\hline Hirudinea & $\begin{array}{l}\text { Leeches } \\
\text { (Hirudo nipponia) }\end{array}$ & $\begin{array}{c}0.20 \\
(0.06)\end{array}$ & $\begin{array}{c}0.18 \\
(0.09)\end{array}$ & -0.65 & 0.51 \\
\hline \multirow[t]{4}{*}{ Insecta } & $\begin{array}{l}\text { Dragonfly nymphs } \\
\text { (Odonata spp.) }\end{array}$ & $\begin{array}{c}0.04 \\
(0.02)\end{array}$ & $\begin{array}{c}0.04 \\
(0.02)\end{array}$ & -0.74 & 0.46 \\
\hline & $\begin{array}{l}\text { Korean water scorpion } \\
\text { (Laccotrephes japonensis) }\end{array}$ & $\begin{array}{c}0.17 \\
(0.08)\end{array}$ & $\begin{array}{c}0.04 \\
(0.02)\end{array}$ & -1.19 & 0.24 \\
\hline & $\begin{array}{l}\text { Korean water mantis } \\
\text { (Ranatra chinensis) }\end{array}$ & $\begin{array}{c}0.03 \\
(0.02)\end{array}$ & $\mathrm{n} / \mathrm{a}^{*}$ & $\mathrm{n} / \mathrm{a}$ & $\mathrm{n} / \mathrm{a}$ \\
\hline & $\begin{array}{l}\text { Japanese predacious diving beetles } \\
\text { (Cybister japonicus) }\end{array}$ & $\begin{array}{c}0.32 \\
(0.06)\end{array}$ & $\begin{array}{c}0.05 \\
(0.04)\end{array}$ & -2.50 & 0.01 \\
\hline \multirow[t]{2}{*}{ Amphibia } & $\begin{array}{l}\text { Tadpoles } \\
\text { (Salientia } \text { spp.) }\end{array}$ & $\begin{array}{c}5.08 \\
(1.79)\end{array}$ & $\begin{array}{c}1.70 \\
(0.77)\end{array}$ & -2.68 & 0.01 \\
\hline & $\begin{array}{l}\text { Black-spotted pond frogs } \\
\text { (Rana igromaculata) }\end{array}$ & $\mathrm{n} / \mathrm{a}$ & $\begin{array}{c}0.05 \\
(0.34)\end{array}$ & $\mathrm{n} / \mathrm{a}$ & $\mathrm{n} / \mathrm{a}$ \\
\hline \multirow[t]{2}{*}{ Actinopterygii } & $\begin{array}{l}\text { Eight-barbel loaches } \\
\text { (Lefua costata) }\end{array}$ & $\begin{array}{c}1.58 \\
(0.66)\end{array}$ & $\begin{array}{c}8.36 \\
(1.81)\end{array}$ & -2.90 & $<0.001$ \\
\hline & $\begin{array}{l}\text { Chinese muddy loaches } \\
\text { (Misgurnus mizolepis) }\end{array}$ & $\begin{array}{c}0.84 \\
(0.12)\end{array}$ & $\begin{array}{c}1.48 \\
(0.21)\end{array}$ & -2.34 & 0.02 \\
\hline
\end{tabular}

Numbers denote the average number of individuals/trap ( $\pm 1 \mathrm{SE})$. Mean ranks were compared between the two areas using the Wilcoxon signed-rank test. " $\mathrm{n} / \mathrm{a}$, data were not applicable because no animals were sampled. 

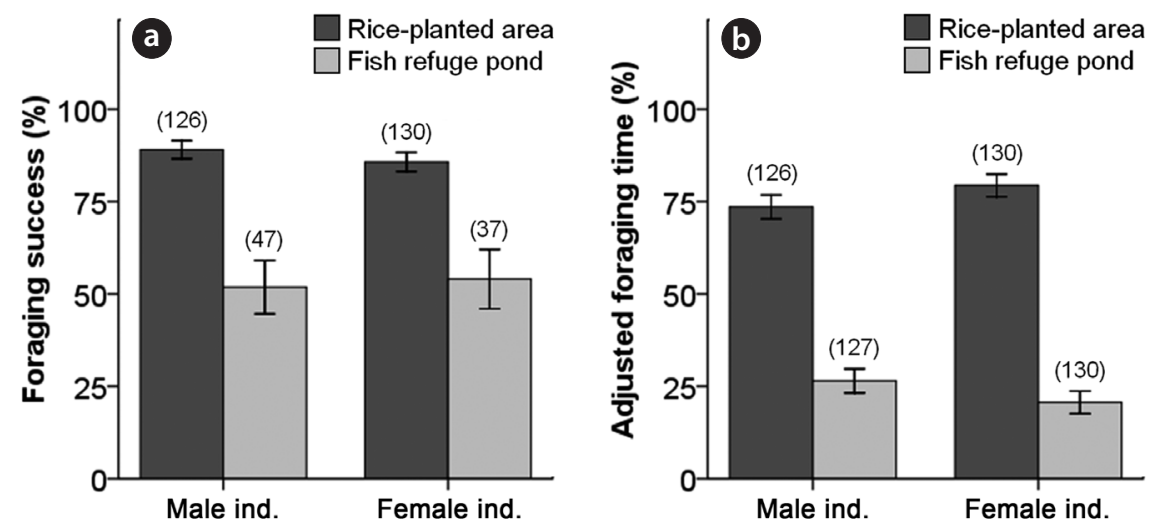

Fig. 3. Foraging behavior of the two captive bred oriental storks released into the paddy fields with a fish-rice farm. (a) Foraging success was accounted for the number of prey captures divided by the number of total foraging attempts. (b) The percentage of foraging time that the oriental storks stayed in the rice-planted area and the fish refuge pond in the paddy fields. The foraging time was adjusted by the area difference between the rice-planted area (95\% of total area) and the fish refuge pond (5\%) in the paddy fields. Each bar denotes mean \pm 1 SE with sample size.

\section{DISCUSSION}

The present study using the two captive bred oriental storks released in a semi naturally constructed paddy field documented how a fish-rice farm was associated with prey abundance and foraging behavior of the oriental storks. Overall, the foraging success of the two oriental storks might positively influence their foraging time in a given area with the fish-rice farming paddy fields.

\section{Rice paddy fields with a fish-rice farm}

The abundance of some aquatic animals was higher in the fish refuge pond than in the rice-planted areas in the paddy fields, suggesting that the deeper water might be preferred by fish while the shallower water might be preferred by tadpoles (see Table 2). A fish refuge is specifically a deeper area provided for the fish within a rice field, which was likely provided in case the paddy field was dried up or not deep enough for fish habitats (reviewed in Halwart and Gupta 2004). Our previous study also indicated that the water depth preference of loaches was sig- nificantly biased to deeper water, and the fish refuge pond in the rice-planted areas increased the presence of the loaches (Jung 2010). The connectivity between the river system and agricultural fields could help loaches spawn appropriately in summer in the rice paddy and then migrate to the river system in winter (Naruse and Oishi 1996, Fujimoto et al. 2008). Considering that water conditions in paddy fields are often unpredictable due to varying rainfalls and harvesting schedules (Katayama et al. 2011), a portion of drainage ditches or fish refuge ponds should provide appropriate and stable habitats for fish in the paddy fields.

\section{Foraging area of oriental storks}

The two captive bred oriental storks foraged mostly fish and unknown small prey (aquatic insects for example) in the rice-planted area and mostly fish in the fish refuge pond. The percentage of captured tadpoles and unknown small prey was higher in the rice-planted area and in the fish refuge pond. The two oriental storks had higher foraging success in the rice-planted area than in the fish ref-

Table 3. Prey types captured by the two captive bred oriental storks released into the paddy fields with a fish-rice farm

\begin{tabular}{|c|c|c|c|c|}
\hline Prey type & $\begin{array}{c}\text { Rice-planted area (\%) } \\
\qquad(N=38)\end{array}$ & $\begin{array}{l}\text { Fish refuge pond (\%) } \\
\qquad(N=38)\end{array}$ & $Z$ & $P$ \\
\hline Fish & $33.69(4.15)$ & $26.64(6.44)$ & -1.50 & 0.13 \\
\hline Tadpoles & $2.62(0.95)$ & $0.88(0.88)$ & -2.12 & 0.03 \\
\hline Frogs & $0.67(0.24)$ & $2.69(2.63)$ & -1.24 & 0.21 \\
\hline Unknown & $35.19(4.60)$ & $9.84(3.40)$ & -3.86 & $<0.001$ \\
\hline
\end{tabular}

Number denotes percent mean ( $\pm 1 \mathrm{SE}$ ). The percentage of captured preys was compared using the nonparametric Wilcoxon signed-rank test. 
uge pond of the paddy fields, and this behavioral pattern was likely associated with the longer time spent foraging in the rice-planted area than in the fish refuge pond. The evidence collected presumably suggests that the oriental storks might forage in the area with fish, tadpoles, and aquatic insects with a greater success rate due to shallow water depth although fish abundance was relatively higher in the fish refuge pond. For instance, in white storks (Ciconia ciconia) the average number of chicks fledged per pair was reduced with increased water level, suggesting that over flooding negatively influenced the efficient capture of prey such as earthworms and small mammals (Tryjanowski et al. 2005). Similarly, high water level in the habitat limited the occurrence of black-necked storks (Ephippiorhynchus asiaticus) by probably negatively affecting foraging conditions (Maheswaran and Rahmani 2001). Thus, it is highly plausible that water level inside paddy fields with a fish-rice farm might interact with habitat use of aquatic animals to shape the foraging success and areas of the captive bred oriental storks.

In conclusion, the paddy fields should be recognized as an alternative wetland and structured to provide a stable refuge for a variety of aquatic animals as well as a suitable foraging area for wetland birds. Although the present study was conducted in a small scale using two captive bred oriental storks, the significance was to disentangle the relationship among food abundance, prey type, foraging success, and area use of a wetland forager in the paddy fields with a fish-rice farm. Future habitat management plans in paddy fields with a fish-rice farm for oriental storks and other wetland species should consider habitat requirements not only for the oriental storks but also for their prey such as fish, amphibians, and aquatic insects.

\section{ACKNOWLEDGMENTS}

We thank E. K. Yang and Y. S. Choi for the field work and M. S. Hyun and H. Y. Lee for the logistics dealing with the transportation and maintenance of the two oriental storks during the study period.

\section{LITERATURE CITED}

Amano T, Kusumoto Y, Tokuoka Y, Yamada S, Kim EY, Yamamoto S. 2008. Spatial and temporal variations in the use of rice-paddy dominated landscapes by birds in Japan. Biol Conserv 141: 1704-1716.

BirdLife International. 2008. Ciconia boyciana. In: IUCN
2010. IUCN Red List of Threatened Species. Version 2010.4. http://www.iucnredlist.org. Accessed 26 November 2011.

Choi YS, Kwon IK, Yoo JC. 2007. Foraging habitat preferences of herons and egrets. J Ecol Field Biol 30: 237-244.

Czech HA, Parsons KC. 2002. Agricultural wetlands and waterbirds: a review. Waterbirds 25(Special Publication 2): 56-65.

Dorfman EJ, Lamont A, Dickman CR. 2001. Foraging behavior and success of black-necked storks (Ephippiorhynchus asiaticus) in Australia: implications for management. Emu 101: 145-149.

Fujimoto Y, Ouchi Y, Hakuba T, Chiba H, Iwata M. 2008. Influence of modern irrigation, drainage system and water management on spawning migration of mud loach, Misgurnus anguillicaudatus C. Environ Biol Fish 81: 185-194.

Halwart M, Gupta MV. 2004. Culture of fish in rice fields. FAO: Italy and The WorldFish Center: Malaysia. http:// www.worldfishcenter.org. Accessed 26 June 2011.

Hata K. 2002. Field experiment on the migration of fishes to a paddy field with a small fishway. Jpn Agric Res Q 36: 219-225.

Jung MR. 2010. A study of habitat environmental characteristics of mudfish inhabited in rich field. MS Thesis. Korea National University of Education, Cheongwon, Korea.

Kano Y, Kawaguchi Y, Yamashita T, Shimatani Y. 2010. Distribution of the oriental weatherloach, Misgurnus anguillicaudatus, in paddy fields and its implications for conservation in Sado Island, Japan. Ichthyol Res 57: 180188.

Katayama N, Saitoh D, Amano T, Miyashita T. 2011. Effects of modern drainage systems on the spatial distribution of loach in rice ecosystems. Aquat Conserv Mar Freshw Ecosyst 21: 146-154.

Lawler SP. 2001. Rice fields as temporary wetlands: a review. Isr J Zool 47: 513-528.

Maheswaran G, Rahmani AR. 2001. Effects of water level changes and wading bird abundance on the foraging behaviour of blacknecked storks Ephippiorhynchus asiaticus in Dudwa National Park, India. J Biosci 26: 373-382.

Moreno-Opo R, Fernández-Olalla M, Guil F, Arredondo Á, Higuero R, Martín M, Soria C, Guzmán J. 2011. The role of ponds as feeding habitat for an umbrella species: best management practices for the black stork Ciconia nigra in Spain. Oryx 45: 448-455.

Naruse M, Oishi T. 1996. Annual and daily activity rhythms of loaches in an irrigation creek and ditches around paddy fields. Environ Biol Fishes 47: 93-99.

Park SR, Cheong SW. 2002. Preliminary study for reintroduc- 
tion of oriental white storks (Ciconia boyciana Swinhoe) in Korea. 8th INTECOL International Congress of Ecology, 2002 Aug 8-11, Seoul. Bumwoo Publishing Company, Seoul, pp 283-292.

Park SR, Kim SK, Sung HC, Choi YS, Cheong SW. 2010. Evaluation of historic breeding habitats with a view to the potential for reintroduction of the oriental white stork (Ciconia boyciana) and crested ibis (Nipponia nippon) in Korea. Korean J Syst Zool 26: 191-196.

Sebastián-González E, Sanchez-Zapata JA, Botella F. 2010. Agricultural ponds as alternative habitat for waterbirds: spatial and temporal patterns of abundance and management strategies. Eur J Wildl Res 56: 11-20.

Sung H, Kim J, Cheong S, Kim S, Jo J, Cheong M, Choi YS, Park SR. 2009. A case study on foraging behavior of oriental white storks (Ciconia boyciana) in the variation of prey density and water depth. Korea J Environ Biol 27: 155-163.

Tryjanowski P, Jerzak L, Radkiewicz J. 2005. Effect of water level and livestock on the productivity and numbers of breeding white storks. Waterbirds 28: 378-382. 